\title{
O PDE E AS SALAS DO PROINFO: ANÁLISE CRÍTICA SOBRE OS PROJETOS COMPENSATÓRIOS NA EDUCAÇÃO
}

\author{
Maria Luzia Ferreira ${ }^{1}$ \\ José Lucas Pedreira Bueno ${ }^{2}$
}

\section{RESUMO}

O presente texto apresenta uma análise dos projetos educacionais presentes em escolas públicas brasileiras, com base em uma perspectiva crítica, que procura descortinar o discurso neoliberal para a construção da excelência na educação. Por meio de uma abordagem qualitativa, busca apontar as disputas que envolvem os segmentos sociais hegemônicos da complexa sociedade capitalista atual, contribuindo para a configuração de uma escola gerenciada conforme os ditames do mercado. A partir da primeira década dos anos 90, os projetos educacionais passaram a fazer parte do cenário das escolas públicas brasileiras, quando a proposta do Banco Mundial consistia em melhorar a qualidade e a eficiência do ensino, mediante a melhoria da aprendizagem dos alunos e da redução das altas taxas de repetência. Desse modo, os projetos educacionais perpetuam a ideia de que questões políticas e sociais devem ser tratadas como questões técnicas, de eficácia/ineficácia. Projetos educacionais são introduzidos nas escolas e alicerçam a ideia de que para solucionar os problemas da educação, deve-se melhorar a "qualidade" do ensino, uma proposta subjacente aos interesses do Banco Mundial.

Palavras-chave: Neoliberal; Banco Mundial; Projetos educacionais.

\section{THE PDE AND ROOMS PROINFO: CRITICAL ANALYSIS ON PROJECTS IN COMPENSATORY EDUCATION}

\begin{abstract}
This paper presents an analysis of the present educational projects in Brazilian public schools, based on a critical perspective that seeks to uncover the neoliberal discourse to build excellence in education. Through a qualitative approach seeks to identify disputes involving complex social segments hegemonic modern capitalist society, contributing to setting a school managed according to the dictates of the market. From the first decade of the 90s, the educational projects became part of the scenario of the Brazilian public schools, when the World Bank proposal was to improve the quality and efficiency of education by improving student learning and reducing high repetition rates. Thus, the educational projects perpetuate the idea that political and social issues should be treated as technical issues, effectiveness / ineffectiveness. Educational projects are introduced in schools and underpin the idea that to solve the problems of education, should improve the "quality" of education, a proposal underlying interests of the World Bank.
\end{abstract}

Keywords: Neoliberal. World Bank. Educational projects. 


\section{INTRODUÇÃO}

O presente texto apresenta uma análise dos projetos educacionais presentes em escolas públicas brasileiras, com base em uma perspectiva crítica, que procura descortinar o discurso neoliberal para a construção da excelência na educação. Por meio de uma abordagem qualitativa, busca apontar as disputas que envolvem os segmentos sociais hegemônicos da complexa sociedade capitalista atual, contribuindo para a configuração de uma escola gerenciada conforme os ditames do mercado.

Nesse contexto, compondo uma política multilateral concebida por organismos internacionais, como Banco Mundial e FMI, faz-se necessário realizar uma abordagem sobre os interesses e a presença destes, face à sua intervenção em promover e alinhar os países em desenvolvimento a um propósito de orientação hegemônica imperialista. A política econômico-social em convergência ao ideário neoliberal estabelecida pelo Estado Brasileiro desde o Governo Fernando Collor de Mello (1990-1992), ratificada pelo Governo do PSDB (1995-2002) e ampliadas pelo Governo de Luís Inácio Lula da Silva (2003-2010) passam, desse modo, a ser reproduzida nos espaços escolares, por meio do financiamento dos projetos educacionais.

A partir da primeira década dos anos 90, os projetos educacionais passaram a fazer parte do cenário das escolas públicas brasileiras, quando a proposta do Banco Mundial consistia em melhorar a qualidade e a eficiência do ensino, mediante a melhoria da aprendizagem dos alunos e da redução das altas taxas de repetência. Desse modo, os projetos educacionais perpetuam a ideia de que questões políticas e sociais devem ser tratadas como questões técnicas, de eficácia/ineficácia. Projetos educacionais são introduzidos nas escolas e alicerçam a ideia de que para solucionar os problemas da educação, deve-se melhorar a "qualidade" do ensino, uma proposta subjacente aos interesses do Banco Mundial.

Em concomitância a este período, e na esteira das mudanças econômicas, os princípios neoliberais, se estabelecem no Brasil, por meio da política de atuação liberal do Presidente Fernando Collor de Mello (1990-2002). Esse novo cenário brasileiro passa a constituir a iniciativa do processo de privatizações, considerando a viabilização da abertura econômica do país, que diante da crise inflacionária, e por meio de projetos de estabilização econômica, dispõe a reestruturação administrativa do Estado, redefinindo seu papel na sociedade. Na esteira das mudanças econômicas, se firma também um compromisso em reformar o ensino brasileiro, propagando desse modo, a tendência de um sistema educativo público pautado nos valores de eficiência do mercado.

Para se efetivar com sucesso as reformas educacionais, e manter a hegemonia capitalista, se constroem conceitos que deliberam o discurso neoliberal. De acordo com Bueno e Gomes (2011), expressões como: "treinamento de habilidades, desenvolvimentos de competências, educação ao longo da vida, voluntariado, parcerias entre o público e o privado", denotam o objetivo alternativo das reformas educacionais do tempo atual.

Como resultado do processo de intensificação dessas reformas e na intenção de se perpetuar e legitimar o ideário neoliberal na educação, por meio da convergência do Ministério da Educação, implantam-se projetos educacionais nas escolas.

Desse modo, os projetos educacionais passam a ser vistos sob uma perspectiva de crescente necessidade, estabelecendo um caráter compensatório, a partir do momento em que se tornam um "remédio" para amenizar ou mesmo proporcionar a "cura" para alguns males da precarização da educação escolar pública. Nesse processo de formação ideológica, as razões sobre a problemática educacional são omitidas, pois perpassam pelas 
condições estruturais do capitalismo, que promovem a desigualdade e a miséria, para além das campanhas publicitárias governamentais.

Dessa forma, os projetos educacionais apresentados nessa discussão, o Plano de Desenvolvimento da Escola (PDE) e Programa Nacional de Tecnologia Educacional (PROINFO), informatização das escolas, contribuem para alicerçar as ideias dos imperativos mercadológicos do capital. Constrói-se, desse modo, a consistente ideia que caracteriza um plano concebido sob os auspícios de uma visão gerencial estratégica, construindo e consolidando uma escola calcada na eficiência administrativa, dita moderna e tecnológica.

Em sua essência o PDE, procura executar e concretizar ações no cotidiano escolar, intensificando a permanente atuação do processo de informatização por meio do PROINFO. Uma parceria promovida entre os projetos educacionais constrói um ajuste de objetivos, de tal modo, que ambos se complementam, ou seja, por meio do PDE e seus recursos, o PROINFO acaba adquirindo destaque e importância na escola, tendo em vista ser um elemento que acolhe o discurso da inclusão tecnológica. Entretanto, há uma realidade nas escolas que esbarra nos eventuais sucateamentos das salas do PROINFO e na conseqüente falta de profissionais para coordenar estes laboratórios tecnológicos, demonstrando uma ambiguidade entre as decisões tomadas pelos gestores e a presente realidade das escolas públicas brasileiras

\section{A INCORPORAÇÃO DAS POLÍTICAS E PROJETOS COMPENSATÓRIOS PELA EDUCAÇÃO ESCOLAR BRASILEIRA}

A hegemonia das proposições neoliberais no Brasil quer seja nos aspectos econômicos, quer seja nos aspectos sociais, materializa-se por meio da reforma do Estado. Concebida por organismos internacionais, a proposição neoliberal no país, propõe uma nova lógica dos direitos universais de cidadania, que reduz gradativamente os direitos sociais, e inicia um processo de substituição desses direitos por políticas assistencialistas e compensatórias.

A essa mesma lógica é incorporada as políticas educacionais, que implicam em configurar e minimizar a atuação do Estado, e dessa forma, constituir e intensificar as reformas promovidas para curto e longo prazo na educação, cujo desdobramento se efetiva no chão da escola. Delineando as propostas concebidas pelo Banco Mundial para homogeneizar a educação, procura-se, nesse artigo evidenciar por meio da análise da implementação de projetos educacionais, o sentido das propostas neoliberais inexoráveis destes projetos. À luz das ideias de Coraggio (2000), é importante salientar que as crises do sistema educacional, que vigoram hodiernamente, já haviam sido interpretadas pelas proposições do Banco Mundial desde os anos 1970, concentrando uma análise voltada para os determinantes socioeconômicos, propondo dessa forma, a ideia de uma escola semelhante a uma empresa. (CORAGGIO, 2000, p. 97)

Em outras palavras, estamos recebendo uma assessoria para reformar nossos sistemas de ensino, baseada em uma teoria questionável: mais que isso, as pesquisas que a assessoria orienta produzem evidencias não conclusivas e até contrárias às próprias hipóteses que norteiam suas recomendações. Isso pode ser explicado em parte por uma conjuntura global que considera a teoria econômica neoclássica como parte da ideologia neoliberal e neoconservadora dominante. (CORRAGIO, 2000, p. 97-98) 
Para Torres (2000), o Banco Mundial não apresenta ideias isoladas, há uma proposta articulada, construída sob a orientação de uma ideologia, que concebe um pacote de medidas para melhorar o acesso, a equidade e a qualidade dos sistemas escolares, nos países em desenvolvimento. Portanto, as políticas e estratégias arquitetadas pelo Banco Mundial reconhecem que cada país possui uma peculiaridade, uma especificidade. Entretanto, em último aspecto, acaba por reformar com os mesmos critérios a educação dos países em desenvolvimento. Nesse sentido, trata-se, de fato, de mecanismos que compreendem articulações que são adotadas aos países em desenvolvimento, e que abrange um amplo conjunto de aspectos associados à reforma educativa universal. (TORRES, 2000)

Em face deste cenário de mudanças e reformas educacionais, pelo qual o Brasil vem passando, há a convergência com as proposições do Banco Mundial. Tendo em vista, que, as decisões tomadas pelos governos convergem com os parâmetros estabelecidos por este organismo, predominantemente, há uma efetiva concretização dos projetos compensatórios. Por meio dessas decisões, os conteúdos e projetos educacionais propostos pelo Banco Mundial, seguem um roteiro pré-concebido, que se alinha à implementação da gestão administrativa e ao planejamento escolar.

Dessa forma, os projetos educacionais são fragmentados nas escolas e acabam tornando-se dispersos sem apresentar uma continuidade sistêmica. Não há, nesse contexto, formulações críticas que levem ao questionamento dessas propostas. Portanto, os projetos passam a ser executados de maneira deslocada, sendo geridos por decisões colegiadas, que pretendem ser democráticas, mas são fortemente influenciadas pelo capital.

Os projetos educacionais apresentados nesta discussão, o PDE (Plano de Desenvolvimento da Escola) e PROINFO (Programa Nacional de Tecnologia Educacional), informatização das escolas, contribuem para alicerçar as ideias dos imperativos mercadológicos do capital. No que se refere ao PROINFO, delineia a expectativa de que a comunidade escolar seja incluída e participe do acesso democrático por meio do processo de informatização tecnológica. Há que ressaltar, desse modo, uma discussão tangencial em relação à penetração das tecnologias no âmbito educacional.

Os projetos educacionais passam a ser vistos sob uma perspectiva de crescente necessidade, estabelecendo um caráter compensatório, que não leva em consideração os efeitos perversos sofridos pelas escolas que não consolidaram seus projetos de tecnologias educativas.

Nesse sentido, entende-se por projetos compensatórios, aqueles que apresentam metas a serem compartilhadas pela comunidade escolar, a fim de atingir a qualidade na educação, utilizando indicadores básicos como índices de reprovação, número de alunos matriculados, entre outros. Esses projetos são beneficiados com grandes somas de recursos ou equipamentos destinados às escolas, de acordo com o significativo índice de reprovação. Os projetos adquirem o caráter compensatório pelo fato de não atingirem a raiz do problema, que se apresenta na estrutura no capital, de modo que apenas "mascara" a situação relacionada ao baixo índice de qualidade educacional presente nas escolas públicas brasileiras, compensando os problemas com uma política que atua apenas quantitativamente sobre o efeito e não sobre a causa.

A execução e implementação desses projetos ocorre por meio de uma gestão democrática dita, eficiente, construída para dispersar noções de racionalidade técnica, nas quais é empregada uma dimensão positivista, que dificulta a formação de uma cidadania crítica. Assim, o discurso presente nos projetos educacionais é alinhavado com o planejamento escolar, de modo a conduzir à busca de resultados satisfatórios que possam atingir porcentagem significativa de rendimentos no processo ensino-aprendizagem. Tendo 
em vista, neste processo evidenciar os indicadores educacionais, a exemplo do Índice de Desenvolvimento da Educação Básica (IDEB), a mensuração das taxas de reprovação, que são empregados como argumento para implantação dos projetos compensatórios no âmbito escolar.

Observa-se que, enquanto projeto compensatório, o PDE possui caráter mantenedor e propagador das propostas neoliberais, uma vez que estreita a atuação dos gestores, de modo que suas ações convergem com os projetos estabelecidos pelo Banco Mundial.

Em relação ao processo de informatização tecnológica das escolas, sob a perspectiva do PROINFO, há um mesmo caminho percorrido para se construir um apaziguamento das condições sociais, contribuindo para consolidar os pilares dos critérios empresariais na educação. Segundo Bueno e Gomes (2011, p.11):

[...] os critérios de "qualidade" que acompanham o advento das TIC na educação e valorizados nas reformas e nas políticas são os de natureza empresarial, tendo como fundamento central o aumento da produtividade. Em sintonia com o contexto neoliberal marcado pela racionalização, desregulamentação, desestatização e liberalização, a educação foi veiculada como um dos elementos de composição na relação competitiva da economia e não apenas como um agente de resgate da dívida social. Ou seja, os enfoques e paradigmas da educação refletem a hegemonia do discurso neoliberal, que enxerga a educação como responsável pela mácondição da mão de obra, tendo essa instituição que ser gerida por critérios empresariais para dar conta das demandas do mercado.

Em sua essência o PDE, procura executar e concretizar ações no cotidiano escolar, intensificando a permanente atuação do processo de informatização por meio do PROINFO. Uma parceria promovida entre os projetos educacionais constrói um ajuste de objetivos, de tal modo, que ambos se complementam, ou seja, por meio do PDE e seus recursos, o PROINFO acaba adquirindo destaque e importância na escola, tendo em vista ser um elemento que acolhe o discurso da inclusão tecnológica. Entretanto, há uma realidade nas escolas que esbarra nos eventuais sucateamentos das salas do PROINFO e na consequente falta de profissionais para coordenar estes laboratórios tecnológicos, demonstrando uma ambiguidade entre as decisões tomadas pelos gestores e a presente realidade das escolas públicas brasileiras. De acordo com Prata (2005, p. 21):

Esta necessidade de atualizar o modelo de educação ao modelo de sociedade depara-se com a constatação de que a maioria das escolas não recebeu ainda condições para se adequar a esta realidade. Muitas dessas sequer atentaram para as mudanças que ocorrem ao seu redor ou um pouco mais distante, ofertando formação muito mais compatível com o modelo de sociedade industrial, ou seja, um ensino tradicional que comparado com as exigências da sociedade do conhecimento é pobre em conteúdo, em diversidade de referências, em tecnologias de aprendizagem.

Para Arruda e Raslan (2010, p. 03-04):

Os estudos privilegiaram a análise e discussão sobre o acesso e utilização dos computadores disponibilizados para as escolas através do PROINFO que apontam a utilização insignificante dos laboratórios de informática devido ao número insuficiente de máquinas e pela falta de conservação e manutenção do funcionamento dos equipamentos e dos softwares, 
número e tamanho do espaço físico dos laboratórios insuficiente para a quantidade de alunos matriculados, por turma, nas escolas públicas brasileiras. Os estudos que focalizaram a formação de professores realizada pelo PROINFO, para utilização dos laboratórios de informática, apontaram: a descontinuidade deste processo; cursos esporádicos e com carga horária insuficiente para cumprimento dos objetivos propostos [...]

Há que se ressaltar, portanto, que há um esforço desmedido em promover a consolidação dos projetos compensatórios, como "tábua de salvação" e como elementos construtores da nova hegemonia, que se forma cotidianamente mediante ações e decisões pautadas na implementação das políticas educacionais.

Trata-se, de mencionar os princípios de incorporação da equidade e de justiça equitativa nas políticas públicas, pois estes termos foram diretamente vinculados à concepção de desenvolvimento econômico, entendido nesse processo como diminuição de diferenças sociais por meio da elevação da capacidade de empregabilidade da população. Por este motivo, os projetos educacionais têm sido articulados com a política de estabilidade e crescimento da economia. (RISCAL, 2011, p. 255).

Nesse sentido, as políticas públicas são incorporadas à concepção de justiça distributiva, passando a promover, também, uma alteração no conceito de democratização, um novo sentido construído ideologicamente pela formação do capital, e deixando de representar os direitos da população na determinação das políticas fundamentais que constituem o Estado, para ser estabelecida como controle democrático de políticas de implementação e gestão. Sob os auspícios dessa bandeira, as políticas públicas são concebidas para garantir e legitimar a sustentabilidade da economia, e não em seu papel de propiciar a redistribuição das condições de produção de renda.

As ações que vem sendo implementadas no campo da educação encontram-se em perfeita sintonia com a orientação das agências multilaterais para os governos latino-americanos que visam a transformação produtiva com equidade e vem gradualmente assumindo papel central na política educativa porque privilegiam a articulação das atividades educativas com o desenvolvimento econômico e a empregabilidade. Durante o governo de Luiz Inácio Lula da Silva, programas que promovem a justiça distributiva em todas as áreas sociais: assistência, saúde, trabalho, educação, e em todos os casos podem ser identificados inúmeros projetos voltados para a contenção da pobreza por meio de ações compensatórias. (RISCAL, 2011, p.256).

Incorporada a esse discurso, as políticas compensatórias em pauta, encontram-se de forma explícita diante da atuação do Ministério da Educação. A concepção de ações compensatórias voltadas à equidade social passa a ser objeto da política educacional mediante orientações traçadas para a educação dos países mais pobres do mundo, de acordo com a Conferência Mundial sobre Educação para Todos, realizada em Jomtien, na Tailândia, em 1990. Nessa conferência, os países signatários entre eles o Brasil, assumiram o compromisso de desenvolver projetos para a equidade e maximização dos recursos financeiros. 


\section{O PROINFO E A INTERIORIZAÇÃO DAS DIRETRIZES DOS ORGANISMOS INTERNACIONAIS}

O desenvolvimento tecnológico educacional ganhou apoio e rapidez em sua consolidação, a partir da segunda metade do século XX, principalmente depois da Segunda Guerra Mundial, quando o processo de inovação e expansão tecnológica passou a fazer parte, de forma mais intensa do cotidiano.

As propostas concebidas para o campo da difusão tecnológica no âmbito educacional ganham força e vigor a partir da década de 1990. Nesse período, no governo do presidente Fernando Henrique Cardoso (1995-2002), ocorre uma reavaliação das políticas voltadas para a informática na educação. Em substituição ao antigo projeto Programa Nacional de Informática Educativa (PRONINFE) criado em 1989, que utilizava o modelo Logos para sua operacionalização, surge o novo modelo PROINFO. No entanto, o PROINFO, apresenta sérios problemas de execução em todas as escolas do país. A formação aligeirada dos professores promovida pelo programa acentuou aspectos referentes à dificuldade de acesso e uso da tecnologia para a sala de aula e mesmo fora dela.

De acordo com Moraes (2010), é possível perceber que com a chegada de equipamentos diversos às escolas (computadores, tevês, aparelhos de DVD, periféricos, entre outros), na maioria dos casos, esses não passam a ser utilizados, ou os mesmo não são incorporados ao Projeto Político Pedagógico. Ressalta ainda que, quando ocorre uma formação para uso das tecnologias promovidas pelo governo estadual ou federal, essa se dá de forma aligeirada, sem ser incorporada organicamente às atividades escolares (MORAES, 2010).

Criado no ano de 1996, o PROINFO tem como objetivo propiciar uma educação voltada para o desenvolvimento tecnológico e educar para uma cidadania global, numa sociedade tecnologicamente desenvolvida (ARRUDA; RASLAN, 2000). Além de ser um projeto concebido para atender a todas as escolas da rede pública de ensino de todos os estados brasileiros, o PROINFO tem a intenção de se consolidar por meio da colaboração efetivada entre o Ministério da Educação, governos estaduais e a sociedade.

Nesse sentido, percebe-se que os projetos educacionais são criados e pensados para se tornarem uma engrenagem que possa fazer parte de um mecanismo ainda mais complexo, de ajuste diante das necessidades do capital. Nesse sentido, a observação de Alves (2006), traz elementos importantes para nossa reflexão:

(...) $\mathrm{O}$ homem, com os mais diferentes recursos, desde o livro suficientemente universalizado até os meios de comunicação de massa e a informática, tem acesso imediato ao conhecimento produzido nos centros científicos mais avançados do mundo e consulta bibliotecas e arquivos das mais expressivas instituições culturais do universo. Mas, paradoxalmente, o conhecimento culturalmente significativo que circula por diversos canais da sociedade, desde caráter privado, como a família e as empresas, até os referentes a muitas instituições públicas, não penetra no espaço da escola, a instituição que celebra como sua a função de transmitir o conhecimento (ALVES, 2006, p. 232)

Com o intuito de promover o discurso da redução, mitigação das desigualdades sociais e inclusão tecnológica, em sua essência, os projetos educacionais, acabam contribuindo para redefinir as formas de pensamento na escola, construindo novas categorias de pensar e agir, de acordo com os interesses do capital, que tem como intuito, 
apenas a formação de mão-de-obra para o mercado de trabalho. Isso demonstra que, mesmo com a introdução das novas tecnologias que se apresenta de forma caricatural nas salas de aula, confirmar-se a repetição dos velhos vícios do material didático, instrumento de trabalho no século XVII, que submeteu o educador ao seu controle, tal qual aponta Alves (2006).

Portanto, a melhoria da qualidade dos serviços escolares tem sido um artificio retórico no discurso oficial que encampou conceitos empresariais como qualidade, eficiência, produtividade, gestão por objetivos e empreendedorismo e, desse modo, constrói-se um sentido liberal de modernidade e avanço nas bases educacionais. Para Moraes (2010, p.13), estas questões reforçam a tendência do discurso de inclusão tecnológica, interiorizado nas escolas e que segue as diretrizes estabelecidas pelos organismos internacionais e explica que:

[...] quando o Banco Mundial argumenta que as novas tecnologias são forças econômicas percebemos que esse discurso pressupõe uma concepção de educação economicista, pois ao não considerar os aspectos culturais que envolvem as dimensões da consciência e da linguagem na educação, o Banco reproduz a racionalidade que mantém a sociedade ofuscada pela sedução da ciência e da tecnologia e dentro delas, as tecnologias da informação e comunicação, autoalimentando o sistema de dominação, tal como se depreende da perspectiva crítica de Adorno e Horkheimer.

Pode-se dizer que a lógica do discurso hegemônico apresenta a inclusão tecnológica como instrumento para o combate à exclusão econômica, o que é um paradoxo. Afinal como combater a exclusão de milhares de trabalhadores se as bases estruturais da sociedade não foram revolucionadas?

Outro aspecto que merece atenção é o apelo ao componente democrático "presente" nas escolhas realizadas pela escola. Na verdade, essas escolhas pautadas e concebidas por meio de ações que não são engendradas pelos gestores, atuam apenas como mero instrumento de regulação e controle social. Para Silva (1999), as pessoas são livres para determinar o que querem, porém aquilo que querem já está determinado antecipadamente, está previamente definido em termos empresariais e industriais.

Nessa perspectiva, Silva (1999, p. 18-19), enfatiza que:

O pensamento neoliberal, em geral no campo educacional, consiste em transformar questões políticas e sociais em questões técnicas. Nessa operação, os problemas sociais e educacionais não são tratados como questões políticas, como resultado e objeto de lutas em torno da distribuição desigual de recursos materiais e simbólicos e de poder, mas como questões técnicas, de eficácia/ineficácia na gerência e administração de recursos humanos e materiais. Assim, a situação enfrentada cotidianamente em nossas escolas por professores, e estudantes é vista como resultado de uma má gestão de recursos por parte dos poderes públicos, como falta de produtividade e esforço por parte dos professores e administradores educacionais, como consequência de métodos atrasados e ineficientes de ensino e de currículos inadequados e anacrônicos.

Considerando Soares (2000, p. 30), “[...] o Banco Mundial vem dando ênfase especial à educação, que é vista não apenas como instrumento de redução da pobreza, mas principalmente como fator essencial para a formação do capital humano, adequado aos 
novos padrões de acumulação". Nesse sentido, é importante observar o caráter regulador e paradoxal dos projetos educacionais, que apresentam condições arbitrárias na prática e pseudodemocráticas em suas propostas.

Entende-se que à medida que o discurso viabiliza a efetivação de uma política educativa que busca essencialmente estabelecer a qualidade na educação, de outra forma, é possível evidenciar em diversos momentos que a prática dos projetos financiados por recursos internacionais, não se efetiva da forma que se propõe. A noção de qualidade na educação tornou-se fruto de um princípio ideológico pautado em demandas educacionais que passam a privilegiar o desenvolvimento econômico do capital em detrimento da igualdade social.

\section{O PDE E A REESTRUTURAÇÃO CAPITALISTA DOS SISTEMAS EDUCACIONAIS BRASILEIROS}

As demandas sócio-educativas do Brasil norteiam um processo histórico que expõe as condições precárias de um país periférico, que incorpora o discurso da qualidade na educação e que por sua vez reforça essas bases a partir da construção de legislação educacional. É importante considerar que, no bojo dessas construções históricas, políticas e sociais, há interferência de organismos multilaterais.

Como parte de um conjunto de medidas para promover a qualidade na educação por meio do desenvolvimento econômico e atingir índices de redução da pobreza, o Banco Mundial, criou o Programa Fundo de Desenvolvimento da Escola (FUNDESCOLA-1998), um financiamento que abrange um conjunto de projetos materializados por meio de diversas ações para o cotidiano das escolas. Um desses projetos, o Plano de Desenvolvimento da Escola (PDE) traduz bem à importância de se atingir as metas pretendidas pelo Banco Mundial. Para Antonini (2006), essa importância se reveste de elementos estratégicos no âmbito das reformas educacionais processadas na América Latina, sobretudo no Brasil, sob a égide de organismos multilaterais, como o Banco Mundial, Fundo Monetário Internacional (FMI) e outras entidades afins.

Com o processo de reestruturação no campo produtivo capitalista, ocorre, por sua vez, uma configuração dos sistemas educacionais brasileiros a partir da formação de teorias de cunho neoliberal. A partir dos anos 1990, surgem propostas voltadas para a gestão da educação básica precedidas por inspirações neoliberais. Para Fonseca (2009, p.234), deliberadamente, "estas propostas fazem parte de um conjunto de mudanças que constituem a reforma do Estado brasileiro". Nessa conjuntura, as demandas apresentadas, pela estrutura produtiva e tecnológica exigem novas perspectivas na formação dos trabalhadores. (FONSECA, 2009, p. 234).

Com um período de intensas mudanças nos campos político, econômico, social e educacional a administração pública passa a imprimir um formato gerencial, que tem como objetivo tornar-se eficiente, flexível e ágil, sugerindo, por sua vez, um desempenho compatível com a atual fase do capitalismo global e competitivo. Nesse sentido, Fonseca (2009, p.240) enfatiza que:

Uma das ações prioritárias foi a descentralização, pela qual foram transferidas funções da burocracia central para estados e municípios e para as denominadas organizações sociais, configuradas como entidades de direito privado, públicas não-estatais. Tais organizações atenderiam a serviços como os de saúde e educação, considerados serviços fundamentais, mas não exclusivos do Estado. Com essa alternativa, o Estado deixaria de ser o responsável direto pelo desenvolvimento 
econômico e social, garantindo para si a definição e o controle das decisões estratégicas. São introduzidos novos projetos e programas, materiais curriculares, estratégias de ensino-aprendizagem, modelos didáticos e outras formas de organizar e gerir o currículo, a escola e a dinâmica da sala de aula.

A reestruturação capitalista, a reforma do Estado Brasileiro e a participação do Banco Mundial contribuíram para alicerçar importantes mudanças promovidas no âmbito escolar. Influenciadas por teorias administrativas capitalistas, constituídas por uma carga de elementos sistematizados, a escola modifica suas atitudes, conteúdos e ideias curriculares, estabelecendo dessa forma, a construção de um novo pensamento pedagógicoideológico na gestão educacional. Conforme Fonseca (2009, p. 240-241):

Na década de 1990 foram desenvolvidas modalidades de gestão que prometiam a melhoria dos indicadores de evasão e repetência, além do rendimento dos alunos, a autonomia e a participação da família, da comunidade educacional e da sociedade em geral em decisões afetas à escola. Compreendia-se, assim, a gestão escolar eficiente como aquela capaz de produzir mais com menor custo, inclusive buscando fontes alternativas para o financiamento da escola.

O Programa FUNDESCOLA foi direcionado inicialmente para algumas regiões do Brasil, especificamente para os estados das regiões Norte, Nordeste e Centro-Oeste, onde passou a ser assimilado e incorporado por municípios e estados. De acordo com Nóbrega (2005, p.28):

Nesse modelo, a União deixa de ser o principal executor das políticas e passa a compor uma instância de coordenação e controle de programas e projetos que são desenvolvidos, sobretudo, pelos estados e municípios. Desta forma, o Estado promove a tão defendida descentralização nos moldes da perspectiva conservadora, apresentando-a como alternativa eficaz na atenuação das desigualdades por meio de uma maior eficiência dos serviços prestados e dos programas sociais implementados.

Primando pela qualidade dos serviços e pela racionalização dos recursos, o PDE se estabelece de forma efetiva no âmbito escolar. Conforme Nóbrega (2005, p. 29):

Percebe-se que a racionalidade que hoje é imposta ao Estado, assim como às políticas educacionais, corresponde à mesma racionalidade do capital, o qual é representado pelas empresas privadas e pelos agentes econômicos. Ademais, no que se referem ao perfil dos gestores educacionais, os requisitos recomendados pela ótica empresarial da qualidade total são a competência técnica e a capacidade de liderança. Tais requisitos estão presentes nos princípios que fundamentam as orientações quanto à implementação dos programas governamentais voltados para o enfrentamento de problemas educacionais do País, como é o caso do Programa FUNDESCOLA - Fortalecimento da Escola.

Sendo gerado na esfera do Programa FUNDESCOLA, financiado pelo Banco Mundial, o PDE tem como princípio básico difundir uma nova perspectiva de administração dos sistemas educacionais (OLIVEIRA, 2005). Portanto, o formato de planejamento que norteia o PDE é o planejamento estratégico, que tem seus principais fundamentos baseados nas teorias da administração de empresas. Significa que esses 
fundamentos são configurados no âmbito educacional, passando, desse modo, a conduzir todo o planejamento educativo.

Nesse sentido, é oportuno lembrar que se trata de uma macro-política que estabelece suas ações por meio das agências internacionais, que interferem no delineamento das políticas educacionais do país e, consequentemente, dos Estados e municípios, que incorporaram prioridades das agendas internacionais em suas próprias orientações para a área de educação, o que é denominado de globalização das agendas educacionais (NÓBREGA, 2005).

Por tratar-se de um projeto vinculado a esta macro-política, os reflexos da implementação do PDE são transferidos para a política educacional local e periférica constituindo o desenvolvimento das ações empreendidas nos Estados e municípios.

Por meio de um planejamento controlador e regulador das atividades realizadas no âmbito escolar, o PDE promove a dissolução da escola, já que, o conjunto de atividades incorporadas ao projeto passa a ser engendrado para que se cumpra um processo articulador de decisões. Portanto, o PDE difunde conceitos administrativos que são disseminados nas escolas, tais como: produtividade, eficácia, eficiência para as teorias, qualidade e inclusão para a aprendizagem. (NÓBREGA, 2005)

Assim, os projetos educacionais pleiteados pelo Programa FUNDESCOLA são estruturados com base em uma visão de gestão administrativa gerencial pautada em conceitos peculiares como a equidade, eficiência, eficácia, complementaridade, qualidade, recorrentes nos diversos projetos. Corresponde, assim, a uma matriz conceitual assentada numa lógica instrumental de planejamento e de gestão. (ANTONINI, 2006).

Para Fonseca (2009), embora haja a construção de um discurso que pleiteia o PDE como um projeto que possibilita o aumento do poder de decisão para as escolas, na prática a própria sistemática veiculada por mecanismos de co-financiamento internacional impõe instrumentos de controle sobre este e outros projetos. No caso do PDE, essa condição ocorre por meio da efetivação dos manuais que são utilizados para acompanhamento e planejamento de ações, além de normas para utilização e prestação de contas dos recursos repassados diretamente à escola.

\section{CONSIDERAÇÕES FINAIS}

Podemos considerar que os projetos educacionais implantados por meio de financiamentos do Banco Mundial visam estabelecer um processo que constituí novos arranjos e modelos para a educação brasileira. Como fio condutor para nosso estudo, apontamos dois projetos educacionais implantados nas escolas, e aqui entendidos como projetos compensatórios, o PDE (Plano de Desenvolvimento da escola) e PROINFO (Programa Nacional de Informática na Educação), ambos concebidos por meio de gerências estratégicas e com o objetivo de implementar uma política de participação democrática e gestão efetiva na esfera escolar.

Mediante a ideia do discurso da qualidade na educação, sustentada por meio da gestão democrática, os projetos educacionais têm sido vistos, como elementos e parte essencial desse processo. Nesse âmbito, propaga a ideia de participação, conquista da qualidade, eficácia, eficiência, gerando o sentimento de que a participação coletiva na escola se efetiva por meio da execução e implantação desses projetos, que constroem pseudodecisões acrescentadas no cerne da escola. Entretanto, salientamos que as propostas 
que se efetivam no âmbito escolar, fazem parte de um projeto maior concebido por órgãos internacionais, como o Banco Mundial.

Nesse sentido, as reflexões aqui realizadas, nos conduziram ao entendimento de que os projetos educacionais, e, consequentemente, do pensamento pedagógico relacionamento à autonomia e à gestão escolar, são elementos da perfeita crença mistificada de que neles se encontram a solução para os problemas da realidade educacional brasileira. Afinal, é possível se efetivar ações concretas e soluções viáveis tendo em vista sermos constantemente controlados por projetos que disseminam uma dominação econômica externa? Faz-se necessário ir além das análises aqui encontradas e procurar construir um pensamento que não esteja vinculado exclusivamente às necessidades e contradições do capital.

Contudo, os projetos educacionais, nessa reflexão, apontados como compensatórios, são paliativos no processo de mitigação dos problemas educacionais. $\mathrm{O}$ caráter ideológico desses projetos apreende uma condição paradoxal, que induz e conduz no chão da escola a resultados equivocados e ineficientes para as perspectivas das especificidades dos problemas educacionais, que têm origem na prática capitalista e não tem dado provas de poderem ser solucionados por medidas que têm as mesmas origens de seus problemas.

\section{REFERÊNCIAS}

ALVES, G. L. A produção da escola pública contemporânea. Campinas: Autores Associados, 2006, p. 232.

ANTONINI, V. L Banco Mundial e política Educacional brasileira: um olhar sobre o Fundescola e o Plano de Desenvolvimento da Escola (PDE). Universidade Estadual Paulista. Faculdade de Ciências e Letras. Campus de Araraquara, 2006.

ARRUDA, E. E. de; RASLAN, V. G. da S. A implementação do programa nacional de informática na educação (PROINFO), no Brasil e no estado de mato grosso do sul, no período de 1997 a 2006. Universidade Federal do Mato Grosso do Sul, 2010. Disponível

em: http://www.histedbr.fae.unicamp.br/acer_histedbr/jornada/jornada7/_GT2\%20PDF/A\%20I MPLEMENTA\%C7\%C3O\%20DO\%20PROGRAMA\%20NACIONAL\%20DE\%20INFO RM\%C1TICA\%20NA.pdf. Acesso em: 17 de Dezembro de 2012.

BUENO. L. P; GOMES, M. A. de O. Uma análise histórico-crítica da formação de professores com tecnologias de informação e comunicação. Revista Cocar (UEPA), v. 5, n. 10, p. 53-64, jul-dez, 2011.

CORAGGIO, J. L. Propostas do Banco Mundial para a educação: sentido oculto ou problema de concepção? In: AUTOR Banco Mundial e Políticas Educacionais. São Paulo: Cortez/PUC-SP, 2000.

FONSECA, M. O financiamento do Banco Mundial à educação brasileira: vinte anos de cooperação internacional. In: AUTOR. Banco Mundial e Políticas Educacionais. Editora Cortez. PUC-SP, 2000. 
MORAES, R. de A. A política Educacional de informática na Educação brasileira e as influências do Banco Mundial. Do FORMAR AO PROINFO: 1987-2005. s/d Disponível:

http://www.histedbr.fae.unicamp.br/acer_histedbr/seminario/seminario7/Resumo/res_raque 1\%20de\%20almeida\%20moraes.pdf Acesso em 20 dez. 2012.

NÓBREGA, C. L. O Plano de Desenvolvimento da Escola (PDE) numa perspectiva de governo democrático popular: uma análise da experiência da rede de ensino de Recife - PE. Dissertação (mestrado) - Universidade Federal de Pernambuco. CE. Educação, 2005.

Disponível: http://www.ufpe.br/ceadmoodle/file.php/1/coord_ped/sala_3/arquivos/CRISTIANE_LIBE RATO_DA_NOBREGA.pdf Acesso em: 15 dez. 2012.

OLIVEIRA, S. M. B. Plano de Desenvolvimento da Escola- PDE: a gestão escolar necessária frente às diretrizes educacionais do Banco Mundial. Universidade Federal de Mato Grosso do Sul. Centro de Ciências Humanas e Sociais. Campo Grande/MS, 2005.

PRATA, C. L. Gestão democrática e tecnologias de informática na educação brasileira pública: o PROINFO no Espírito Santo. Porto Alegre: Universidade do Rio Grande do Sul, 2005.

SILVA, T. T. da. A nova direita e as transformações na pedagogia da política e na política da pedagogia. In: AUTOR: Neoliberalismo, Qualidade Total e Educação. Cidade: Visões Críticas. 1999.

SOARES, M. C. C. Banco Mundial: políticas e reformas. In: AUTOR. Banco Mundial e Políticas Educacionais. São Paulo: Cortez/PUC-SP, 2000.

RISCAL, S. A. Política Educacional, Justiça Distributiva e equidade: considerações sobre as políticas compensatórias para a educação. HISTEDBR on-line, n. 44, p. 248261, dez 2011.

TORRES, R. M. Melhorar a qualidade da educação básica? As estratégias do Banco Mundial. In: AUTOR. Banco Mundial e Políticas Educacionais. São Paulo: Cortez/PUCSP, 2000.

\footnotetext{
Notas

${ }^{1}$ Universidade Federal de Rondônia - UNIR, Porto Velho/Brasil

${ }^{2}$ Coordenador do Programa de Pós-Graduação em Educação Escolar - Mestrado Profissional da Universidade Federal de Rondônia., Líder do Grupo Educa e professor do DED/UNIR
}

Recebido: julho/13 Aprovado: agosto/13 